\title{
Conductometric and Spectrofluorimetric Studies of Cationic Gemini Surfactant in Aqueous Solutions
}

\author{
Halide Akbaş ${ }^{1}$ and İkbal Sarıkaya ${ }^{2}$
}

\begin{abstract}
The critical micelle concentration (cmc) of the cationic gemini surfactant was evaluated using the conductivity measurements. The conductivity as a function of surfactant concentration was measured at different temperatures and the data were used the find $\mathrm{cmc}$ and degree of counterion dissociation of the micelle $(\alpha)$. Thermodynamic parameters were also obtained from the temperature dependence of the cmc values. The micelle aggregation numbers $\left(\mathrm{N}_{\mathrm{agg}}\right)$ of cationic gemini surfactant in aqueous medium has been obtained using steady state fluorescence quenching technique. The micropolarity of the systems was also evaluated from the ratio of intensity of peaks $\left(I_{1} / I_{3}\right)$ of the pyrene fluorescence emission spectrum.
\end{abstract}

Keywords - cationic gemini surfactant, critical micelle concentration, krafft temperature, aggregation number.

\section{INTRODUCTION}

Surfactants are amphiphilic compounds containing both hydrophobic groups (their tails) and hydrophilic groups (their heads) [1]-[3]. A special class of surfactants, the so-called geminis, are constructed by connecting any two identical or different conventional monomeric amphiphilic moieties with a spacer group [4],[5]. The potential applications of gemini surfactants are in detergents, cosmetics, chemical industry, biological and biomedical fields [6]. Constantly growing interest in the investigation and synthesis of novel dimeric surfactants is a consequence of their superior properties in comparison to conventional surfactants [7]. They are usually much more efficient than the corresponding monomeric surfactants. The critical micelle concentration of a gemini surfactant is typically 10-30 times lower than that of a regular monomeric surfactant with the same hydrocarbon chain length [8]. In view of all these features, they are used in many applications. Therefore, it is important to understand their behavior with other surfactants [9].

Halide Akbaş ${ }^{1}$ is Department of Chemistry, Faculty of Sciences, Trakya University, 22030 Edirne, TURKEY

İkbal Sarıkaya ${ }^{2}$, Department of Chemistry, Faculty of Sciences, Karadeniz Technical University, 61080 Trabzon, Turkey.

\section{II.MATERIALS AND METHODS}

\section{A. Materials}

3-(dimethylamino)-1-propylamine, 1,6 dibromohexane, decanoyl chloride, acetone, chloroform, pyrene, cetylpyridinium chloride.

\section{B.Methods}

\section{Synthesis of cationic gemini surfactant}

The gemini surfactant was synthesized and purified in our laboratory. The synthesis of the gemini surfactant was realized two steps.

Docanoyl chloride $(0.3 \mathrm{~mol})$ was added slowly to 3(dimethylamino)-1-propylamine $(0.3 \mathrm{~mol})$ in chloroform, under dry, under inert atmosphere of nitrogen. The first step product was formed after $24 \mathrm{~h}$. We obtained $\mathrm{C}_{9} \mathrm{H}_{19} \mathrm{CONH}$ $\left(\mathrm{CH}_{2}\right)_{3} \mathrm{~N}\left(\mathrm{CH}_{3}\right)_{2}$ colorless, viscous liquid. After first step the cationic gemini surfactant was synthesized by refluxing 1,6dibromohexane with $\mathrm{C}_{9} \mathrm{H}_{19} \mathrm{CONH}\left(\mathrm{CH}_{2}\right)_{3} \mathrm{~N}\left(\mathrm{CH}_{3}\right)_{2}$ (molar ratio 1:2) in dry acetone with continuous stirring at $80^{\circ} \mathrm{C}$ for $24 \mathrm{~h}$. At the end of the two steps we obtained (Fig. 1) cationic gemini surfactant. All the synthesized compounds were characterized with FT-IR, ${ }^{1} \mathrm{H}$ and ${ }^{13} \mathrm{C}$ NMR.

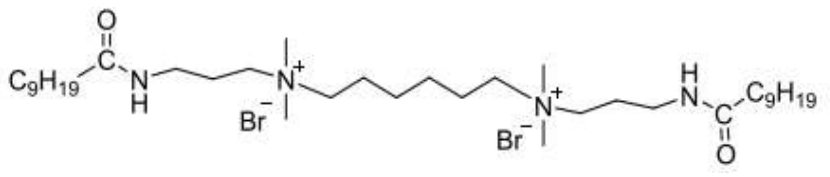

Fig.1 Cationic gemini surfactant

\section{Determination of cmc by conductivity measurements}

The conductivity of single and mixed surfactant solutions was measured by a WTW Terminal 740 with cell constant $0.433 \mathrm{~cm}^{-1}$ in doubly distilled water at five different temperature (from $303,15 \mathrm{~K}$ to $323,15 \mathrm{~K}$ ). Conductivity measurements were used to determine the CMC and the $\alpha$ value of the single and mixed surfactant solutions. The conductivity was measured by addition of stock solution successively in pure water. The binary solutions were prepared by mixing the gemini and conventional surfactant 
solutions in 1:4;2:3;3:2 and 4:1 ratios. The cmc values were obtained at the break point of the specific conductivity surfactant concentration isotherms.

Determination of Aggregation Number by Fluorescence measurements

The micellar aggregation numbers $\left(\mathrm{N}_{\mathrm{agg}}\right)$ of surfactant solutions were determined using steady-state fluorescence measurements at excitation wavelength of $335 \mathrm{~nm}$. Cetylpyridinium chloride monohydrate was used as a quencher and pyrene as probe. Emission spectra of solutions were recorded in the range $350-450 \mathrm{~nm}$. $\mathrm{I}_{0}$ and $\mathrm{I}$ are the fluorescence intensities in the absence and presence of quencher, respectively, for the first vibronic peak in the pyrene emission spectra. Aggregation number values were determined by keeping $\left[\mathrm{C}_{\text {Surf }}\right]$ at ten times of cationic gemini surfactant's CMC. The surfactant solution was added and the pyrene concentration was kept at constant $2 \times 10^{-6} \mathrm{M}$ concentration. As the quencher concentration was varied from 0 to $9.10^{-5} \mathrm{M}$. All the fluorescence measurements were carried out at $25{ }^{\circ} \mathrm{C}$. The micelle aggregation number can be calculated by using the following equation [10]. $\mathrm{T}$ The plots give straight lines in all the cases, and the values of $\mathrm{N}_{\mathrm{agg}}$ are obtained from the slope.

$$
\ln \left(\frac{\mathrm{I}_{0}}{\mathrm{I}}\right)=\frac{\mathrm{N}_{\mathrm{agg}}[\mathrm{Q}]}{[\mathrm{S}]-\mathrm{CMC}}
$$

where [S] is the total surfactant concentration, [Q] is the quencher concentration, and I and Io are the fluorescence intensities of pyrene in the absence and presence of quencher, respectively.

\section{RESUlTS AND DISCUSSION}

The critical micelle concentration $(\mathrm{cmc})$ and degree of counterion values $(\alpha)$ of cationic gemini surfactant estimated through conductometric experiments, at all the studied temperatures $(298.15 \mathrm{~K}, \quad 303.15 \mathrm{~K}, \quad 308.15 \mathrm{~K}, 313.15 \mathrm{~K}$, $318.5 \mathrm{~K}, 323.15 \mathrm{~K})$ are listed in Table 1 . The change of the slope in specific conductivity vs. concentration plot demonstrates that the molecular aggregates or micelles start to form at the concentration corresponding to the break point [11]. An increase in the cmc values can be seen with increasing temperature. As can be seen, the $\mathrm{cmc}$ values for the cationic gemini surfactant, were much lower than that DTAB . $\alpha$ is obtained as the ratio of the slope of the linear plot in the post-micellar region to that in the pre-micellar. Various thermodynamic parameters viz., Gibbs energy of micellization $\left(\Delta \mathrm{G}_{\text {mic }}^{\mathrm{o}}\right)$, enthalpy of micellization $\left(\Delta \mathrm{H}_{\text {mic }}^{\mathrm{o}}\right)$ and entropy of micellization ( $\Delta \mathrm{S}_{\mathrm{mic}}^{\mathrm{o}}$ ) of the cationic gemini surfactant are calculated from experimental data of conductivity. The $\Delta \mathrm{G}_{\mathrm{mic}}^{\mathrm{o}}$ values are found to be negative in all the cases and listed in Table I. Micellization is affected by temperature as the by temperature as the hydrophobic and hydrophilic interactions change with temperature. The critical micelle concentration versus temperature studies have been performed to obtain information on the interactions. As the temperature increases the degree of hydration of the hydrophilic group decreases, which favors micellization; however, an increase in temperature also causes the disruption of the water structure surrounding the hydrophobic group and this is unfavorable to micellization.

TABLE I

VALUES OF EXPERIMENTAL CRITICAL MICELLE CONCENTRATIONS (CMC), MICELLAR DISSOCIATION DEGREE $(\alpha)$ AND THERMODYNAMIC PARAMETERS, OBTAINED FROM EXPERIMENTAL DATA OF CONDUCTIVITY.

\begin{tabular}{ccccccc}
\hline Temp.(K) & $\mathbf{2 9 8 . 1 5}$ & $\mathbf{3 0 3 . 1 5}$ & $\mathbf{3 0 8 . 1 5}$ & $\mathbf{3 1 3 . 1 5}$ & $\mathbf{3 1 8 . 1 5}$ & $\mathbf{3 2 3 . 1 5}$ \\
\hline $\begin{array}{c}\mathrm{CMC} \\
(\mathrm{mmol} / \mathrm{L})\end{array}$ & 0.96 & 0.99 & 1.04 & 1.11 & 1.17 & 1.24 \\
$\alpha$ & 0.28 & 0.30 & 0.31 & 0.33 & 0.35 & 0.36 \\
$\Delta \mathrm{G}_{\mathrm{mic}}^{\mathrm{o}}$ & -46.76 & -46.82 & -47.08 & -47.18 & -47.11 & -47.10 \\
$(\mathrm{~kJ} / \mathrm{mol})$ & & & & & & \\
$\Delta \mathrm{G}_{\mathrm{m}, \mathrm{tail}}^{\mathrm{o}}$ & -23.38 & -23.41 & -23.54 & -23.59 & -23.55 & -23.55 \\
$(\mathrm{~kJ} / \mathrm{mol})$ & & & & & & \\
$\Delta \mathrm{H}_{\mathrm{mic}}^{\mathrm{o}}$ & -13.73 & -14.01 & -14.39 & -14.75 & -15.03 & -15.35 \\
$(\mathrm{~kJ} / \mathrm{mol})$ & & & & & & \\
$\Delta \mathrm{S}_{\mathrm{mic}}^{\mathrm{o}}$ & 0.111 & 0.108 & 0.106 & 0.104 & 0.101 & 0.100 \\
$(\mathrm{~kJ} / \mathrm{mol})$ & & & & & & \\
\hline
\end{tabular}

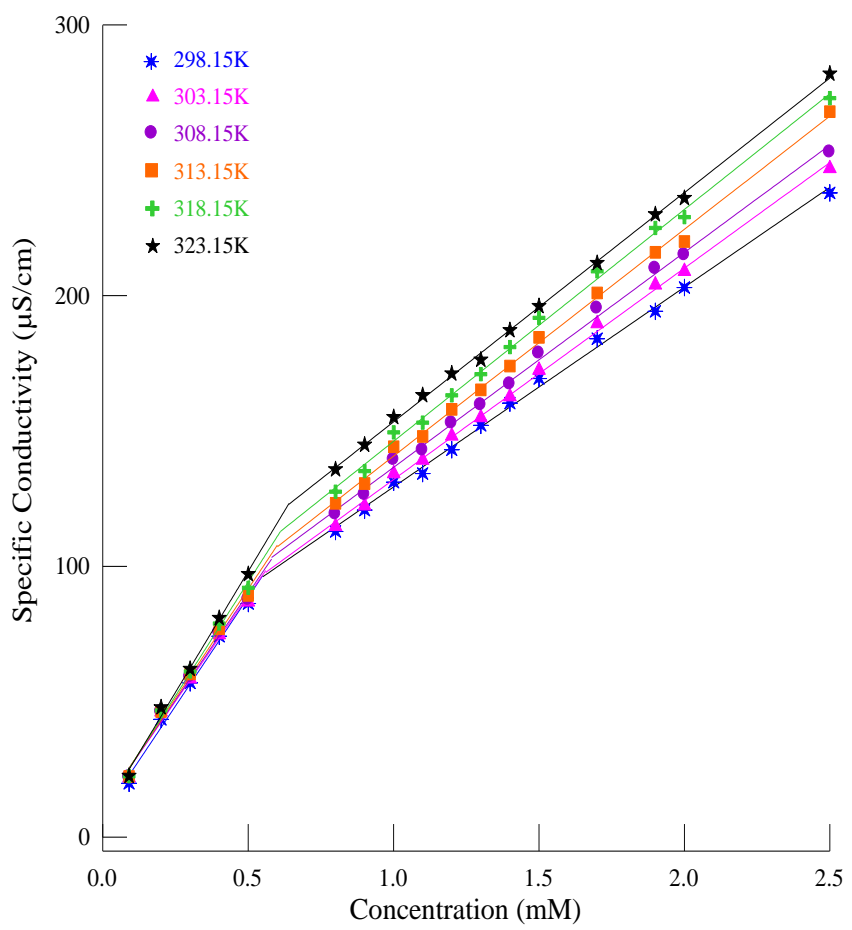

Fig.2 Plots for determination of cmc values of cationic gemini surfactant solutions at different temperature. 


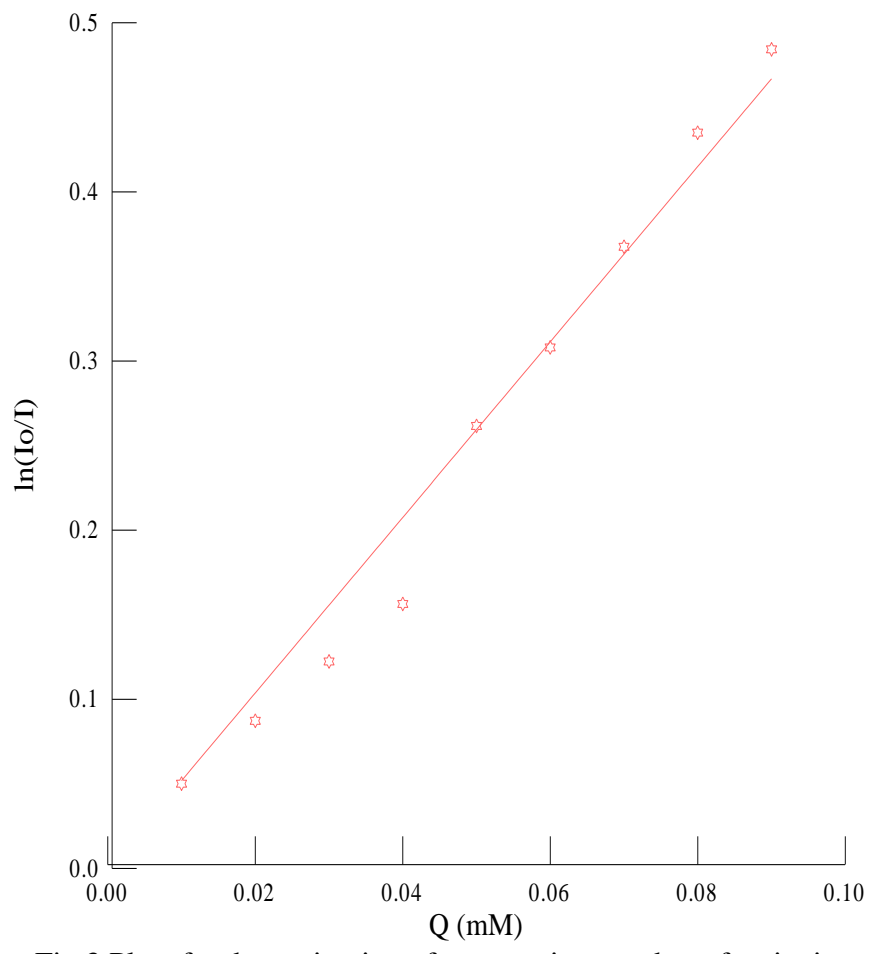

Fig.3 Plots for determination of aggregation number of cationic gemini surfactant.

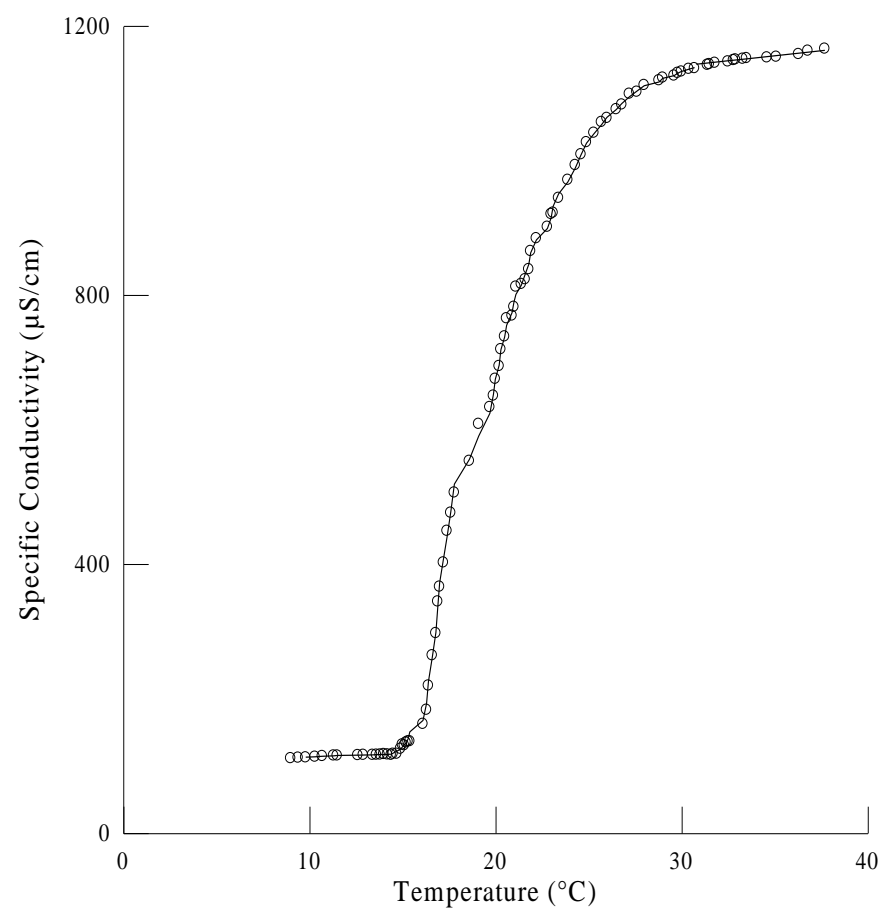

Fig.4 Plots for determination of Krafft Temperature of cationic gemini surfactant solution $(\% 1 \mathrm{w} / \mathrm{v})$

The entropy change is positive in all cases. However, it decreases with increasing temperature. Fig. 3 shows the relationship between $\mathrm{Q}$ and $\ln \left(\mathrm{I}_{0} / \mathrm{I}\right)$ for cationic gemini surfactant. The concentrations of the surfactants used are all $10 \times \mathrm{cmc}$. The plots give straight lines in all the cases, and the values of $\mathrm{N}_{\text {agg }}$ are obtained from the slope of each straight line. The aggregation number of cationic gemini surfactant is found to be 34 and Krafft temperature is found to be $29.6^{\circ} \mathrm{C}$.

\section{CONCULUSION}

Gemini surfactants are superior in their properties and show better performance over the conventional surfactants. enthalpy of micellization $\left(\Delta H_{\text {mic }}^{o}\right)$ values become more negative with the rise in temperature, whereas entropy of micellization $\left(\Delta \mathrm{S}_{\mathrm{mic}}^{\mathrm{o}}\right)$ values remain roughly constant for most of the systems. The micellization process is exothermic in nature and its magnitude is strongly depend on the temperatures.

\section{ACKNOWLEDGMENT}

The authors greatly acknowledge the financial support of this work by Trakya University Research Fund under grant 2014-110.

\section{REFERENCES}

[1] E.K. Kang, B.M. Lee, H.A. Hwang, J.C. Lim, “A novel cationic surfactant having two quaternary ammonium ions," Journal of Industrial and Engineering Chemistry, vol. 17, pp. 845-852, October 2011. https://doi.org/10.1016/j.jiec.2011.09.001

[2] M. Kruk, "Access to ultralarge-pore ordered mesaporous materials through selection of surfactant/swelling-agent micellar templates," Accounts of Chemical Research, vol.45, pp.1678-1687, Oct.2012. https://doi.org/10.1021/ar200343s

[3] J.C. Lim, E.K. Kang, J.M. Park, H.C. Kang, B.M. Lee, "Syntheses and surface active properties of cationic surfactants having multi ammonium and hydroxyl groups, "Journal of Industrial and Engineering Chemistry, vol. 18, pp. 1406-1411, February 2012. https://doi.org/10.1016/j.jiec.2012.01.040

[4] F.M. Menger, J.S. Keiper, "Gemini Surfactants :Reviews," Angewandte Chemie International Edition vol.39, pp.1906-1920, 2000. https://doi.org/10.1002/1521-3773(20000602)39:11<1906::AIDANIE1906>3.0.CO;2-Q

[5] R.Zana, "Dimeric and oligomeric surfactants. Behavior at interfaces and in aqueous solution:A review," Advances in Colloid and Interface Science vol. 97, pp.205-253, March 2002. https://doi.org/10.1016/S0001-8686(01)00069-0

[6] J. Aslam, U. S. Siddiqui, I.A. Bhat, Kabir-ud-Din. "Molecular interactions of cationic gemini surfactants (m-s-m) with an environmental friendly nonionic sugar-based surfactant (b-C12G): Interfacial, micellar and aggregation behavior". Journal of Industrial and Engineering Chemistry vol.20 pp.3841-3850, 2014.

https://doi.org/10.1016/j.jiec.2013.12.088

[7] M. Sikiric, I. Primožic, Y. Talmon, N. Filipovic-Vincekovic. "Effect of the spacer length on the association and adsorption behavior of dissymmetric gemini surfactants," Journal of Colloid and Interface Science vol. 281 pp.473-481, 2005. https://doi.org/10.1016/j.jcis.2004.08.140

[8] H. Akbas, M. Boz, A. Elemenli. "Interaction between cationic gemini surfactant and related single-chain surfactant in aqueous solutions," Fluid Phase Equilibria vol.370 pp. 95-100, 2014. https://doi.org/10.1016/j.fluid.2014.02.024

[9] H.Akbaş, S.Kasapoglu, M.Boz. "Aggregation behavior and intermolecular interaction of binary surfactant mixtures based on cationic Geminis and nonionic surfactants," Colloid Polym Sci vol.293,pp.3429-3437 2015. https://doi.org/10.1007/s00396-015-3702-9

[10] M.BHen-Moshe, S. Magdassi, "Surface activity and micellar properties of anionic gemini surfactants and their analogues" Colloids and Surfaces A: Physicochem., Eng. Aspects vol.250 pp.403-408, 2004 https://doi.org/10.1016/j.colsurfa.2004.01.044

[11] A.J. Khanam, M.S. Sheikh, I.A. Khan, Kabir-ud-Din, "Aggregational behavior of alkanediyl- $\alpha, \omega$-bis(tetradecyldimethylammonium) dibromide series with ionic and nonionic hydrotropes at different temperatures, "Journal of Industrial and Engineering Chemistry,vol.20, pp.3453-3460, December 2014

https://doi.org/10.1016/j.jiec.2013.12.034 
Halide Akbas, is an associate professor of physical chemistry, in the chemistry department at Trakya University. She graduated from the Technical University of Istanbul and received her Ph.D. at Trakya University in 1993. Her research area focuses on novel surfactants, their thermodynamic properties and interactions. and surface chemistry.

İkbal Sarıkaya is a research assistant of physical chemistry, in the chemistry department at Karadeniz Technical University. She graduated from the Trakya University in 2008. Her research area focuses on novel surfactants, surface chemistry, thermodynamic properties and energy. 